\title{
El fin del arte según Danto: visiones críticas
}

The end of art according to Danto: critical visions

\author{
Óscar Ortega Ruiz \\ Departamento de Filosofía, Universidad de Sevilla y Málaga (oscaror9@msn.com)
}

Recibido el 09 de diciembre de 2017; revisado el 10 de enero de 2018; aceptado el 18 de febrero de 2018; publicado el 21 de marzo de 2018

RESUMEN: Durante los años ochenta y noventa, Arthur Danto desarrolló su célebre teoría del fin del arte, que dio lugar a críticas y comentarios por parte de filósofos y artistas. Algunos de los argumentos de esta polémica provenían de focos tan alejados, en principio, de la órbita estética como la filosofía analítica o el positivismo lógico. No obstante, como trataré de mostrar, estas posturas remiten en última instancia a dos célebres concepciones del arte, pertenecientes a la tradición estética europea.

PALABRAS CLAVE: Arte, hegelianismo, hermenéutica, juego, filosofía analítica.

\begin{abstract}
During the eighties and nineties, Arthur Danto developed his famous theory of the end of art, which led to criticisms from philosophers and artists. Some arguments of this controversy came from aparently distant sources from the aesthetic realm like logical positivism or analytic philosophy. However, as I will try to show, these positions refer ultimately to two famous conceptions of art of the European aesthetic tradition.
\end{abstract}

KEYWORDS: Art, hegelianism, hermeneutics, play, analytic philosophy.

Arthur Danto (1924-2013) fue un destacado crítico de arte y profesor de filosofía estadounidense. Alcanzó notoriedad gracias a títulos como La transfiguración del lugar común (Danto, 2009), originalmente aparecido en 1981, y Después del fin del arte (Danto, 1999) publicado en 1997, donde lleva sus razonamientos hasta el extremo, anunciando no su desaparición, pero sí el asentamiento definitivo de un arte posterior a los grandes discursos, un arte después del arte o arte posthistórico (Danto, 1999, p. 65 y ss). Para él, la aparición de fenómenos artísticos como los ready-made y el pop art marcan el fin del gran relato del arte occidental al tiempo que revelan su autoconciencia final 
(Danto, 1999, p. 147). Con dichas tendencias, que integran objetos reales presentados como obras de arte, los artistas empezaron a cerrar la brecha entre el arte y la realidad, de forma que el espectador ya no pudo discernir entre ambas valiéndose tan solo del ojo desnudo. Para la identificación y consideración de la obra de arte será necesario, desde entonces, tomar en cuenta la perspectiva interna del artista (Danto, 2002, p. 231).

\section{Las tesis de Danto bajo el prisma de Hegel y Gadamer}

Siguiendo la argumentación de Danto, la historia del arte se dividiría en dos grandes relatos principales. El primero, que identifica con las tesis del teórico del cinquecento Giorgio Vasari, concibe el arte como actividad representacional, una suerte de búsqueda a través del tiempo tendente a perfeccionar “apariencias visuales”. Según Danto, este relato finaliza con la aparición del cine debido a su mayor capacidad de retratar la realidad. El otro relato fue definido por el crítico estadounidense Clement Greenberg en términos de un ascenso del arte a sus condiciones identificatorias o, más específicamente, una indagación de lo que diferencia a la pintura de cualquier otro arte y que Greenberg encontró en las condiciones materiales del medio. Este último relato llegó a su final cuando el arte reconoció que la obra no tenía que ser de ninguna manera especial. Era la época de consignas como "cualquier cosa es una obra de arte" o "cualquiera es un artista" como dijo Beuys. Habría terminado entonces la pesquisa del arte en pos de su identidad filosófica a través de los diferentes estilos y etapas históricas. La historia del arte, estructurada mediante relatos había, según Danto, llegado a su fin (Danto, 1999, pp.147-150).

Cabe advertir en las afirmaciones de Danto fuertes influencias hegelianas. Recordemos que, para Hegel, el arte constituye el movimiento mediante el cual el espíritu absoluto se comprende a sí mismo a través de la creación de formas materiales. El final del arte conllevaría el ascenso a un nivel de autocomprensión reveladora que hiciese innecesarias búsquedas ulteriores. Esta visión del arte como despliegue de un relato legitimador autocomprensivo contrasta fuertemente con otras visiones de la experiencia artística que la entienden como movimiento continuamente evolutivo. Así, para Gadamer, el juego es fundamental para comprender la experiencia artística. El arte es juego, como cualquier manifestación de la cultura, aunque en un sentido especial: en el hombre se da una tendencia natural hacia el arte, quizás incluso como forma de comunicación anterior al lenguaje. Todo jugar es también un "ser jugados", una experiencia conducida por el propio juego y su poder de fascinación, un "automovimento" o "autorrepresentación”, donde el propio juego se hace a sí mismo. 
Esta dinámica ofrece representaciones transformadoras de lo representado que repercuten en un incremento de la autoconciencia del espectador, en un intercambio de potencialidades virtualmente inagotables.

\section{El arte después de la filosofía según Joseph Kosuth}

Brevemente hemos descrito la postura filosófica que defiende la existencia en el arte de un potencial dialéctico que, según Danto, habría llegado a su fin. Una década antes de que Danto diese a conocer sus tesis, un joven artista llamado Joseph Kosuth, publicaba el ensayo Art after Philosophy (Kosuth, 1969), en el que defiende la postura que podríamos considerar como diametralmente opuesta: la constatación durante el siglo XX del agudo declive de la filosofía y la emergencia paralela de un nuevo potencial renovador en el arte.

Realmente podríamos entender el trabajo de Danto como una fuerte reacción en contra de la postura expuesta por Kosuth, quien declara obsoleta la visión formalista, basada en el análisis físico de los objetos artísticos, por no agregar nada a nuestra comprensión de la naturaleza del arte, ya que asume e incorpora apriorísticamente los límites en su comprensión y posibilidades, haciendo imposibles cuestionamientos ulteriores acerca de su naturaleza. Para Kosuth, el acontecimiento que marca el camino hacia una nueva posibilidad de creación de sentidos en el arte fue la aparición del ready-made de la mano de Marcel Duchamp.

Se trata de una perspectiva que permite el cuestionamiento autorreflexivo de la naturaleza del arte, llevado a cabo desde el seno de la propia práctica artística. De esta forma, el arte cambia su objeto, pasa de estar centrado en problemas formales para acceder a un estado de cuestionamiento acerca de su función, en un paso de la "apariencia" al "concepto". Como es fácil de comprender, las tesis expuestas por Kosuth propiciaron un importante impulso en la revalorización de la obra de Duchamp tras años de decaimiento.

Kosuth expone que sus argumentos se apoyan en reflexiones del filósofo positivista británico Alfred J. Ayers, particularmente en la distinción que propusiera entre las proposiciones analíticas y sintéticas (Ayers, 1992). Según esta formulación, una proposición es analítica cuando su validez depende únicamente de las definiciones de los símbolos que contiene y sintética cuando su validez está determinada por hechos de la experiencia. Para Kosuth, las obras de arte se asemejan a las 
proposiciones analíticas, pues no aportan ninguna información acerca del mundo de la experiencia, no se refieren a hechos. Su función es la de expresar el contenido o consecuencia formal de definiciones del arte. El artista no se ocupa de las propiedades físicas de las cosas, sino del crecimiento conceptual que su obra puede aportar. El arte halla su sentido en su propia y continua redefinición.

\section{La crítica de Joseph Margolis a los postulados de Danto}

En su artículo de 1998 Farewell to Danto and Goodman (Margolis, 1998), el filósofo norteamericano Joseph Margolis realiza una serie de observaciones respecto a la idea de Danto, al que se refiere como un hegeliano tardío, de que el arte ha entrado en una fase "post histórica" en la que no cabe esperar nuevos acontecimientos ni relatos y en la que todo está permitido. Margolis plantea la siguiente pregunta: ¿no podría ser que la afirmación de que el arte ha trascendido su propio relato legitimador o hegemónico sea, sencillamente, la última etapa de esa misma narración? Si tenemos esto en cuenta se evaporaría la pretensión de Danto de que el arte ha terminado, lo cual, para Margolis, suena tan insostenible como anunciar el final de la historia humana.

Para Margolis, la distinción de algo como obra de arte radica en su confrontación con la realidad; los atributos artísticos vienen dados gracias a la habilidad argumental de su autor, mediante la cual redefine intencionalmente los objetos del mundo sensible. La producción artística depende de la manera en que el autor transforma lo existente por medio de su creatividad e imaginación, aún cuando no altere sus propiedades materiales. Según Danto, sólo a través de la asociación retórica de ciertos atributos no discernibles podemos considerar a "cosas meramente reales" como obras de arte. Nada existe en sí como obra de arte. Para Margolis, esta supuesta indiscernibilidad no se da en un contexto cultural comprensivo de los motivos intencionales del autor: resulta imposible imaginar un modo neutral de percepción en donde tenga cabida dicha equiparación, pues toda forma de ver está vehiculada por una serie de rasgos ideológicos y culturales que le son inseparables (Margolis, 1998, p. 374).

La percepción ya predispone a una particular forma de ver; el carácter cognitivo del arte implica la existencia de una serie de elementos externos con capacidad de determinar nuestra forma de apreciarlo. Si percibimos la relación de hechos físicos contenidos en una obra de teatro, entonces ¿cómo negar que también "percibamos" la actuación de los actores o el discurso artístico de 
Shakespeare al ver Hamlet? De forma similar, quedamos predispuestos a percibir el mundo imaginativo de las obras de arte individuales tras la percepción de sus cualidades en el mundo real. El principal error del planteamiento de Danto consiste en no tomar en cuenta que la contemplación de las obras de arte se realiza desde una postura cultural intencional. No tiene sentido separar las propiedades sensibles de los rasgos conceptuales, correspondientes a todo trabajo artístico o cultural (Margolis, 1998, p. 371). El “es” de la existencia física y el "es” de su significado cultural son ambos igualmente válidos.

Podríamos calificar la postura de Margolis como la de un realista cultural, para quien el contexto y la intencionalidad con que un objeto es creado o presentado son absolutamente inseparables del propio objeto. Según su opinión, Danto incurre en los abusos habituales de la tradición analítica estadounidense, consistentes en marginar la historia y la intencionalidad social- cultural, pretendiendo reducir las ciencias humanas a las ciencias físicas. Margolis, por el contrario, defiende que las últimas estarían sometidas epistemológicamente a las primeras.

\section{La postura de George Dickie}

El también filósofo norteamericano George Dickie, en sus obras de 1974 Art and the aesthetic (Dickie, 1974) y El círculo del arte (Dickie, 2005) de 1984 expone la que se ha denominado su Teoría Institucional del Arte. En sus inicios, esta teoría surge como complemento y, posteriormente, a partir de su reformulación de 1984, se erige como rival de las tesis de Danto. Dicha teoría no contiene una definición cerrada, sino abierta y social del fenómeno artístico. Los artistas, al plantearse crear una obra, se marcan como objetivo influir, repercutir en lo que denomina la "institución del arte". Dicha institución es un ente colectivo o cuerpo social formado por museos, fundaciones, críticos, académicos, galerías, coleccionistas, etc.

A Dickie se le ha criticado frecuentemente la circularidad en la que cada uno de los elementos está interrelacionado en su concepción del mundo del arte, de forma que se presuponen y apoyan. Para responder a esta objeción recurre al argumento de que todo individuo utiliza el concepto de obra de arte de un modo satisfactorio permitiendo la acumulación de información adicional sin necesidad de definir explícitamente términos. La circularidad de las definiciones, considerada por muchos filósofos un grave defecto lógico, muestra el carácter flexional del arte en el cual todos los roles se apoyan para construir un todo. Toda obra de arte accede a la categoría de tal gracias al respaldo de la 
institución que denomina mundo del arte. Ser una obra de arte es un estatus frente al telón de fondo de dicha institución (Dickie, 1997, p. 88). La teoría de Dickie, gracias a su carácter hermenéutico y flexional, admite potencialmente toda clase de objetos nuevos creados por el arte del futuro, lo que evita la existencia de lo que Danto definía como agotamiento conceptual en el ámbito del arte.

\section{Conclusiones}

Es fácil asociar las tesis de Danto del final del arte con otras visiones que estuvieron vigentes a finales del siglo XX, como la expuesta por Lyotard acerca del descrédito de los grandes discursos legitimadores o la representada por Fukuyama y su fin de la historia y del dinamismo social tras el triunfo del liberalismo. Un tiempo triste en el que la osadía, la imaginación, el atrevimiento y el idealismo de las empresas humanísticas se verían reemplazados por el cálculo económico y la resolución de problemas técnicos.

La respuesta a la pregunta planteada por Margolis acerca de la posibilidad de que la afirmación de que el arte ha agotado su propio relato legitimador sea, simplemente, la última etapa de esa misma narración, irá siendo paulatinamente relativizada, a la vez que respondida, entendemos, por la emergencia de nuevos enfoques teóricos y artísticos, máxime en esta época de ampliación global de visiones del mundo, en la que las incorporaciones de nuevas perspectivas provenientes de antiguas periferias como la china o la india son tan relevantes. Ya ahora, advertimos que Danto se ciñe a un itinerario claramente centrado en una comprensión del discurrir del arte contemporáneo desde la óptica estadounidense incurriendo, como ha señalado Margolis, en posturas reduccionistas de la tradición analítica de aquel país.

Resulta evidente que los puntos de vista debatidos en esta polémica remiten, como telón de fondo, a dos concepciones del arte en gran parte antagónicas: por un lado, la hegeliana, en la que el arte se presenta como despliegue de un relato revelador abocado a un final que, en el caso de Danto, se presenta no como advenimiento idealista de un nivel superior de autoconciencia, sino más bien como agotamiento argumentativo. Por el otro lado tendríamos la concepción gadameriana, en donde situaríamos a sus críticos, donde el arte se nos muestra como un juego hermenéutico virtualmente perpetuo, en el que la sociedad dialoga dinámicamente con ella misma. 
Entendemos que, solo abusando de postulados materialistas y formalistas que relativizan su valor conceptual, puede anunciarse un agotamiento definitivo del arte. Esta fijación de Danto en el medio de expresión en detrimento del concepto se evidencia en la opinión que tuvo del cine como acelerador de este supuesto final. Fenómenos como el ready-made han hecho, ciertamente, que el centro de atención se haya decantado firmemente hacia el concepto en detrimento de la apariencia de la obra, sin que ello signifique que lo que se pierda en esta mutación sea el arte en sí pues, con Kosuth, opinamos que lo fundamental de la experiencia artística es su capacidad de ampliación de contenidos teóricos y no el estatuto formal de los objetos a los que eventualmente recurre para su emergencia y plasmación.

\section{Referencias bibliográficas:}

AYERS, Alfred (1992). Lenguaje, verdad y lógica. Universitat de València. Servei de Publicacions.

DANTO, Arthur (2002). La transfiguración del lugar común. Paidós: Barcelona.

DANTO, Arthur (1999). Después del fin del arte. Paidós: Barcelona.

DICKIE, George (1974). Art and the aesthetic. Cornell University Press: Nueva York.

DICKIE, George (2005). El círculo del arte. Paidós: Barcelona.

DICKIE, George (1997). Introduction to Aesthetics: An Analytic Approach. Oxford University Press USA: Nueva York.

FUKUYAMA, Francis (1994). El fin de la historia y el ultimo hombre. Planeta-De Agostini: Barcelona.

GADAMER, Hans-Georg (2003). Verdad y Método. Editorial Sígueme: Salamanca.

HEGEL, Georg Wilhelm Friedrich (2015). Filosofía del arte o Estética. Abada editores: Madrid. 
LYOTARD, Jean-François (2006). La condición postmoderna. Editorial Cátedra: Madrid.

KOSUTH, Joseph (1969). “Art after Philosophy”, Studio International, $n^{\circ}$ 915: Londres.

MARGOLIS, Joseph (1998). "Farewell to Danto and Goodman", British Journal of Aesthetics, vol. 38, $n^{\circ} 4$ : Oxford. 